\title{
TESTAMENTOS DE MUJERES GUANACASTECAS: UN APORTE A LA HISTORIA REGIONAL DE GUANACASTE, COSTA RICA. 1774-1826
}

Testaments of "guanacastecas" women: a contribution to the regional history of Guanacaste, Costa Rica. 1774-1826

\author{
Edgar Solano Muñoz \\ Universidad de Costa Rica, Costa Rica \\ edgar.solano@ucr.ac.cr
}

Recibido: $29-05-2020$

Aprobado: 24-07-2020

Edgar Solano Muñoz es historiador. Posee una Maestría en Ciencias Sociales con Mención en Integración Regional por Universidad Nacional de Costa Rica. Es Doctor en Historia por la Universidad de Costa Rica. Se desempeña como profesor e investigador en la Sede de Guanacaste de la Universidad de Costa Rica.

\section{RESUMEN}

El propósito del artículo es explicar las cualidades de los textos testamentarios a partir de una muestra de 18 testamentos de mujeres guanacastecas entre 1774-1826. Para ello, se utilizan protocolos coloniales que contienen la "última voluntad" de mujeres que llevaron sus vidas y su actividad productiva en el contexto de la hacienda ganadera. Se concluye que los manifestado en las clausulas testamentarias nos provee insumos para interpretar el imaginario religioso y la participación de las mujeres dentro de la actividad ganadera del norte de Costa Rica en el siglo XVIII.

Palabras clave: historia; Guanacaste; ganado; mujeres; testamentos

\section{ABSTRACT}

The purpuse of the article is to explain the qualities of testamentary texts a sample of 18 "wills" of "Guanacastecas women" between 1774-1826. To do this, colonial protocols containing the "last will" of women who led their lives and productive activity in the context of livestock farming are used. It is concluded that those manifested in the testamentary clauses provide us inputs to interpret the religious imaginary and the active participation of women within the livestock activity of the northern Costa Rica in the eighteenth century.

Keywords: history; Guanacaste; livestock; women; unsealed will 


\section{Puntos de referencia: la hacienda ganadera y los testamentos coloniales}

Guanacaste es el espacio geográfico en Costa Rica en el cual se originó históricamente la hacienda ganadera. En el último tercio del siglo XVII la ganadería "levanta vuelo" como una actividad económica permanente. El tráfico de mulas en primera instancia y luego, el arribo de hacendados provenientes de Nicaragua hacen que en el norte de Costa Rica la hacienda ganadera tome forma. Tal y como se ha indicado es en

"la jurisdicción de Aranjuez y posteriormente en la de Esparza... situación que se evidencia en el padrón realizado en 1688, acerca del número de familias avecindadas en los valles de Bagaces comprendidos entre los ríos de Chome y el Salto - Tempisque (jurisdicción de Esparza)" (Quirós, 1990, p. 203).

Mapa 1. Ubicación de las haciendas ganaderas en Guanacaste.

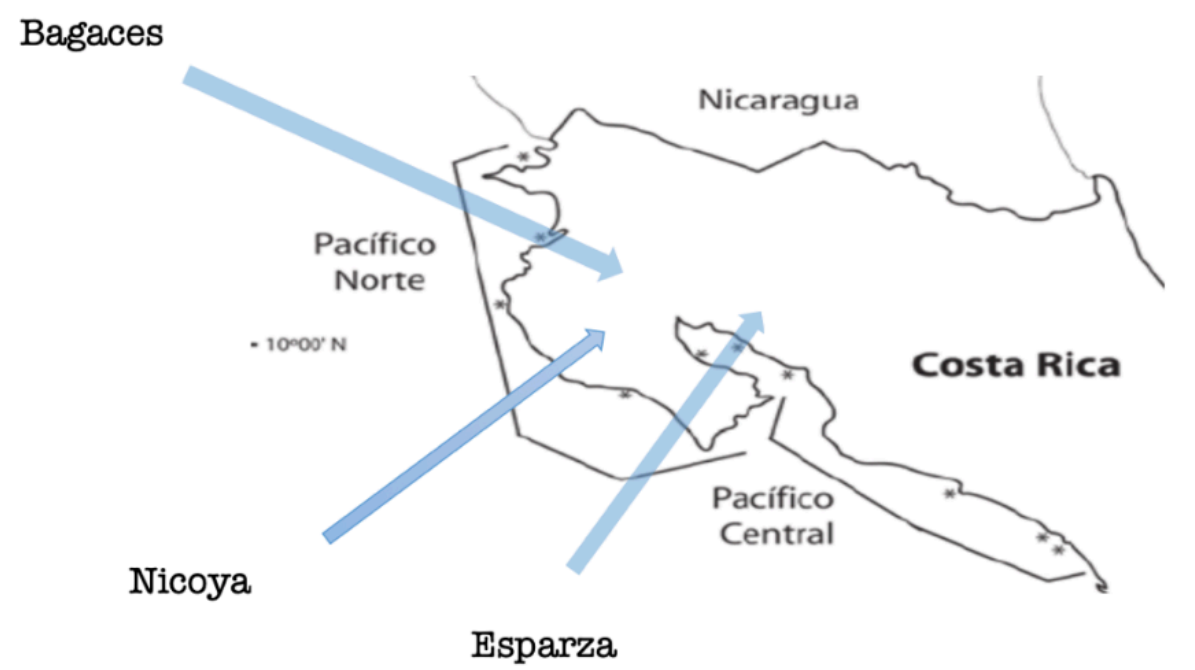

Fuente: Elaboración propia.

Así desde el siglo XVII la zona de Guanacaste se convirtió en el epicentro de la actividad ganadera del país, incluso hasta la actualidad. La ganadería moldea la economía, la cultura y la identidad de los pobladores de esta zona de Costa Rica. 
Tal y como se indicó, en el último tercio del siglo XVII se empiezan a constituir grandes latifundios por parte de hacendados nicaraguenses que detectaron que la zona norte de Costa Rica ofrecía muy buenos pastos, agua y tierras con relieve propicio para el desarrollo de la actividad ganadera. Por supuesto, que la otrora apertura del camino de las mulas a partir del 1660 impulsó el negocio del transporte de migrantes, mercaderías e ideas desde Guatemala hasta Panamá, siendo Guanacaste una zona de importancia logística dentro de esa dinámica comercial colonial.

La hacienda ganadera ha sido el objeto de estudio de múltiples investigaciones desde varios ángulos teórico-metodológicos. ${ }^{1}$ Para nuestros intereses investigativos, dichos textos se constituyen en puntos de referencia que nos permiten conocer de cerca el contexto y características de la hacienda ganadera guanacasteca no solo en el siglo XIX sino un siglo atrás. Por ejemplo, uno de los más emblemáticos (Sequeira, 1985) quien ha analizado la constitución de las haciendas a mediados del siglo XIX y sus vinculaciones con otras actividades productivas del periodo colonial, como por ejemplo con la explotación forestal y el comercio de reses con Nicaragua. Además -junto a los otros autores- nos facilitan un esquema interpretativo de los mecanismos tras los cuales se instauran redes de poder y negocios a todo lo largo de la cuenca del río Tempisque en un largo trayecto temporal que se desarrolla durante el siglo XVII.

\footnotetext{
${ }^{1}$ La historiografía ha sido muy amplia entorno al tema de la hacienda ganadera en Guanacaste. En este caso referenciamos solamante algunos textos que consideramos cardinales. Entre ellos tenemos: Matarrita Ruiz, Mario. (1980). La Hacienda ganadera colonial en el corregimiento de Nicoya, siglo-XVIII. San José, Costa Rica. Gudmundson Kristjanson, Lowell. (1983). Hacendados políticos y precaristas: la ganaderia y el latifundio guanacasteco, 1800-1950. San José, Costa Rica: Editorial Costa Rica. Estratificación socio-racial y económica de Costa Rica: 1700-1850. (1978). San José, Costa Rica: EUNED. "Apuntes para una historia de la ganadería en Costa Rica". (1979). En: Revista de Ciencias Sociales. №17.18, San José: Editorial de la Universidad de Costa Rica. Meléndez, Chaverri Carlos. Costa Rica: tierra y poblamiento en la colonia. (1977). San José, Costa Rica: Editorial Costa Rica. Edelman, Marc. La lógica del latifundio. (1998). San José: Editorial Universidad de Costa Rica.
} 
Mapa 2. Distribución de las haciendas ganaderas en Guanacaste durante el siglo XIX.

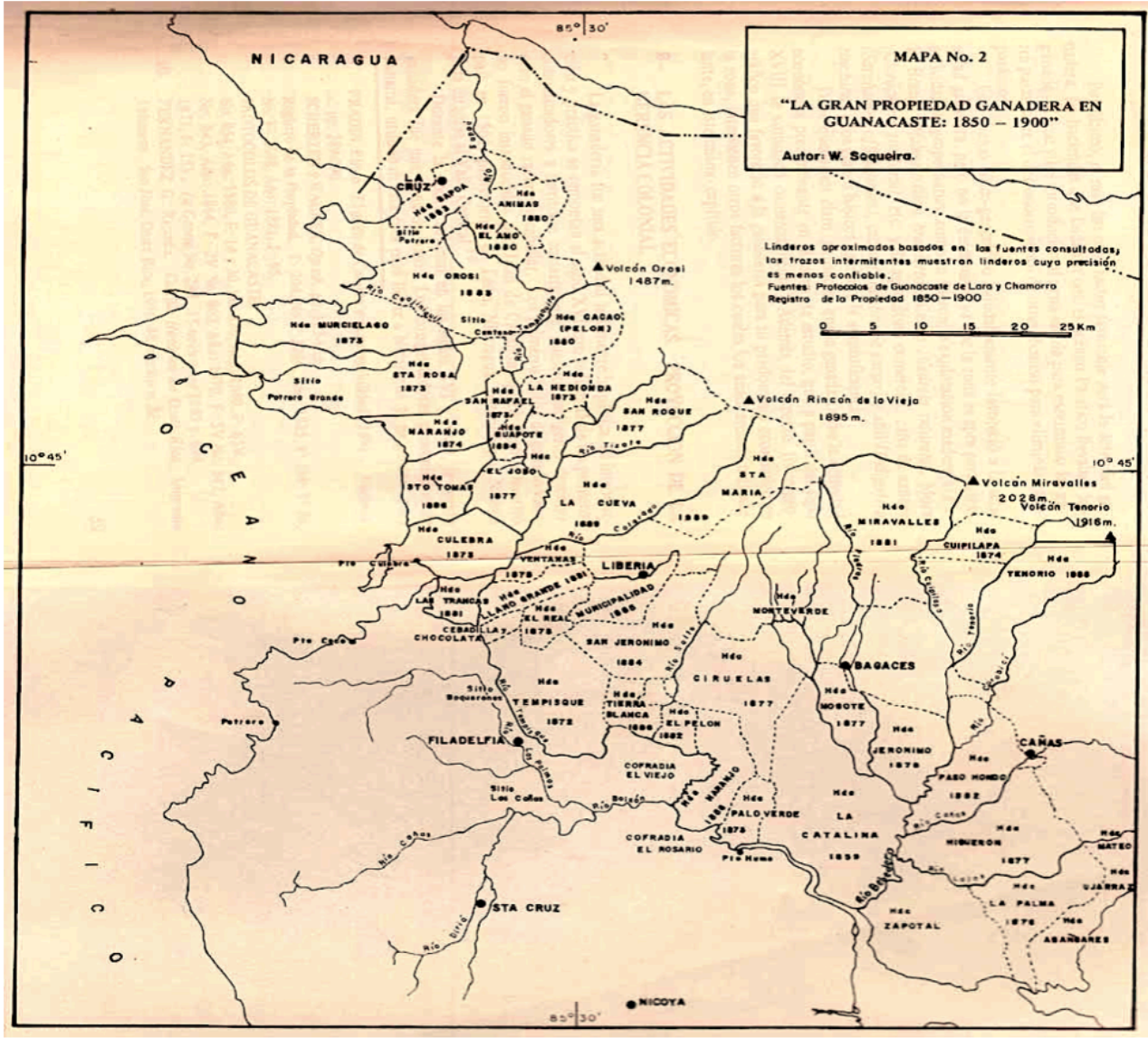

Fuente: Wilder Sequeira, 1985, Cap. II.

Dentro de la dinámica de la sociedad colonial pero específicamente dentro del universo de la hacienda ganadera encontramos al "gamonal" o dueño de la hacienda, los "mandadores" de finca, los peones y las cocineras. Estas últimas

"eran aquellas mujeres encargadas de la casa de la hacienda, muchas de ellas concubinas y madres de los hijos ilegítimos del patrón. No solo atendían las necesidades del gamonal, si no que se encargaban de la alimentación de los trabajadores y de las actividades domésticas y de granja en la unidad productiva" (Rivera, 2009, p. 14). 
Quizá las fuentes históricas han sido una limitante para abordar a la mujer en otras funciones dentro de la hacienda ganadera. Sin embargo, en el caso que nos ocupa, las fuentes testamentales nos proveen valiosa información de la situación de las mujeres que declaran su última voluntad mediante testamentos y con ello, nos proporcionan una fuente para aproximarnos a sus vidas, haberes y sentimientos.

En cuanto a los estudios sobre testamentos encontramos (Schumann, 2020) quien aborda a las mujeres de "alcurnia" en la ciudad de Guatemala en el periodo colonial desde la perpectiva de la religiosidad y su próximidad redes familiares de poder (Schumann, 2012). Ortego Agustín (1999), por su parte, nos lleva al estudio de la situación de las mujeres respecto al ordenamiento jurídico en España durante el siglo XVII. Se hace énfasis en las normar jurídicas regulatorias de las herencias, dote y gananciales. De hecho, sostiene que tanto las cartas de dote como los testamentos nos permiten una

\footnotetext{
"aproximación al trasfondo ideológico de la época; pues a partir de aquí todo un mundo de creencias religiosas, leyes y costumbres que están en el ideario de las gentes de la época se despliega en estos formularios, donde los escribanos o sus ayudantes introducían los nombres de sus clientes y las razones de sus negocios" (Ortego, 1999, p. 262).
}

Un aspecto presente dentro de las motivaciones que llevan a la redacción de los documentos testamentarios tanto en hombres como en mujeres, es la noción de la muerte. Después de las epidemias que atacaron a Europa en los siglos XIV y $\mathrm{XV}$ se acentúa la muerte como un hecho doloroso y temido. Las personas sin distingo de arraigo socio-económico, guardan recelo ante la hora final, y por ello toman las medidas respectivas (Sánchez, 2014, p.952). Así disponen por escrito ante escribano público del destino de sus haberes materiales y a la vez, hallan un auxilio espiritual que "puede resultar decisivo para obtener la condenación o la salvación del alma del difunto y es extremadamente útil para aliviar o acortar la estancia del alma en el Purgatorio" (Sánchez, 2014, pp. 941-966).

Es evidente que en la elaboración de los testamentos se da la combinación de dos conjuntos de motivaciones, la material y la espiritual. Deslindar una de otra es una tarea complicada para el investigador. Lo trascendente se mezcla con lo tangible y en medio se encuentra la hora de la muerte como línea divisoria entre un acto jurídico, por un lado, y por otro de justicia divina. Por ello Sánchez anota con justa razón "el testamento es el mejor medio para que la muerte no alcance desprevenido al ser humano" (2014, p. 952). 
De esta forma la "peregrinación hacia el Cielo" -para aquellos que podían hacerlo- se pautó a partir de la redacción del testamento. Descargar la conciencia y alivianar el alma son las dos operaciones presentes en la emisión de la "última voluntad" testamental. Tal y como lo expresa (Ariès, 1992) el testamento es "un contrato de seguridad concluido entre el individuo mortal y Dios, por mediación de la Iglesia" (p. 959). ${ }^{2}$

Tanto en Europa como en América en la trazabilidad del testamento existe un beneficio para las temporalidades de la Iglesia. Como veremos en el segundo segmento de este artículo, tanto en Costa Rica como en otras partes del mundo, buena parte de los bienes o recursos económicos terminaron en la fundación de capellanías o cofradías. "Fundaciones de memorias perpetuas y capellanías eran dotadas con mayor o menor generosidad, dependiendo de la capacidad económica de cada uno, con bienes raíces, escrituras censuales o juros, que se ponían en cabeza de la Iglesia o Monasterio correspondiente" (Sánchez, 2014, p. 958).

En el contexto costarricense, el tema de los testamentos ha sido abordado específicamente para la provincia de Cartago. Valga anotar que dicha ciudad fungió como la capital de Costa Rica entre 1563 y 1823, de ahí que la mayor parte de los procesos sucesorios se llevaran a cabo en este sitio. En esta línea encontramos una base de datos elaborada por (Alfaro y Velásquez, 2012) en la cual se registran 243 testamentos coloniales de Cartago. ${ }^{3}$

Dentro de la misma investigación, Carmela Velázquez desarrolla un estudio sobre el testamento como fuente para el estudio de las mentalidades colectivas en la sociedad colonial del siglo XVII. En particular se levantan testamentos otorgados entre los años 1607 y 1699.

\footnotetext{
${ }^{2}$ Al hurgar más en los documentos eclesiásticos nos encontramos una formalización doctrinal de las frases que expresa Ariès. v.gr. Constituciones sinodales dadas por el Cardenal Pacheco y promulgadas y ahora aumentadas por el arzobispo Cristóbal Vela. Archivo Catedral de Burgos (A.C.B.), cód. n53, fols. 33v-45. En línea: http://www.catedraldeburgos.es/

${ }^{3}$ Alfaro, F. y Velázquez, C. (Setiembre 2011- Febrero 2012). Base de Datos de los Testamentos de Cartago, Costa Rica, del Siglo XVII. Diálogos. Revista Electrónica de Historia. Vol. 12 № 2.
} 


\footnotetext{
"Todos esos testamentos forman parte de las fuentes notariales asentadas en los protocolos de Cartago. El protocolo es el libro en donde el notario o el escribano deja asentadas las manifestaciones de los comparecientes en relación con contratos que les interesan, o bien, donde queda constancia de las manifestaciones de testigos o de hechos que ha tenido a la vista cuando ha actuado como receptor de pruebas" (Velásquez, Setiembre 2011-Febrero 2012, p. 197).
}

En síntesis, Velásquez va desde la descripción del papel de los protocolos coloniales hasta las motivaciones materiales y espirituales de quienes "testan" en la sociedad cartaginesa del siglo XVII. También se hacen otras consideraciones sobre los componentes legales y socioeconómicos contenidos en la "última voluntad" de los individuos testantes.

Finalmente, encontramos los aportes de Arnaldo Moya Gutiérrez (1991) quien explora el rito mortuorio en la ciudad de Cartago durante el siglo XVIII. Moya también hace hincapié en las creencias y los sentimientos implicados el rito mortuorio ya que este representa un rasgo de la cultura de los vecinos cartagineses. Señala que el testamento "otorgaba la virtud de conciliar el paso por este mundo con lo sobrenatural. Como un acto formal, su otorgamiento daba fe de la buena disposición del testador para cumplir con los preceptos exigidos por la lglesia" (Moya, 1991, p.25).

\section{Los testamentos de mujeres guanacastecas en el contexto de la hacienda ganadera}

Para desarrollar el estudio se hizo una selección de 18 fuentes testamentales de mujeres de Guanacaste entre 1769 a 1826. Ellas se ubican en la serie Protocolos Coloniales del Archivo Nacional de Costa Rica y específicamente los podemos hallar registrados en el Índice de Protocolos de Guanacaste que recopila todo tipo de transacciones a partir de 1756 (ver Imagen 1). 
Imagen 1. Índice de Protocolos de Guanacaste

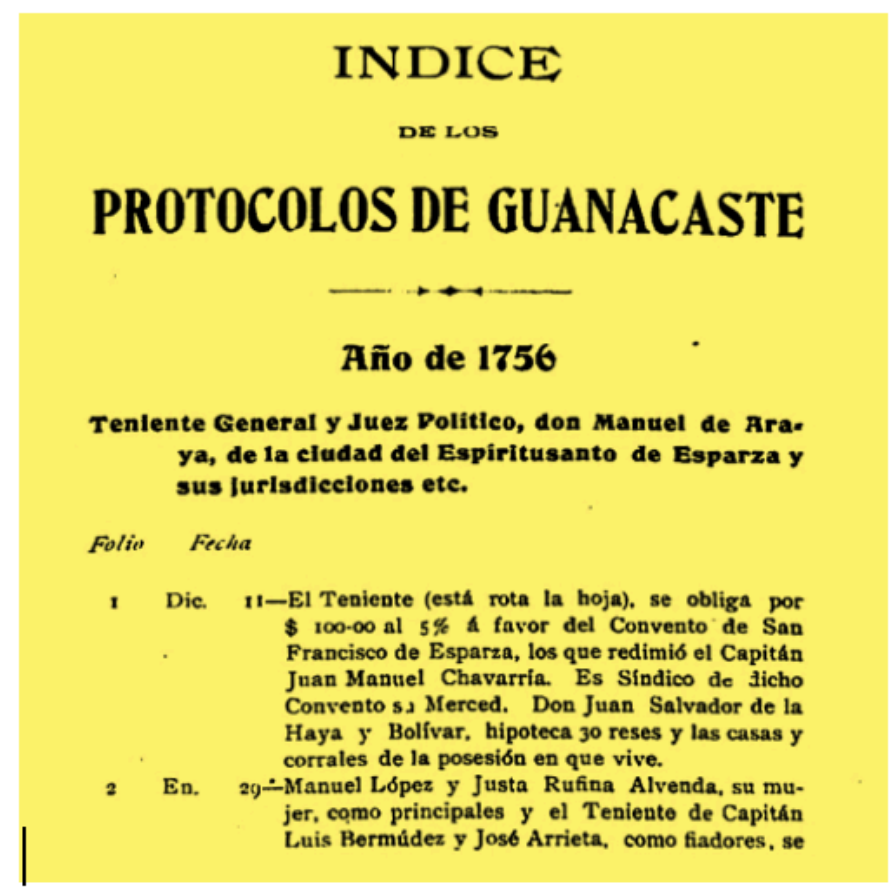

Fuente: Manuel de Araya, 1902.

Tal y como se indicó páginas atrás, la matriz doctrinaria presente en la redacción de cada testamento en Guanacaste así como en el resto de la provincia de Costa Rica, derivó de las normas emitidas en la sesión XXV del Concilio de Trento en el decreto sobre el "Purgatorio". De hecho, en torno al tema de las herencias y testamentos este señala

\footnotetext{
"Mas cuiden los Obispos que los sufragios de los fieles, es a saber, los sacrificios de las misas, las oraciones, las limosnas y otras obras de piedad, que se acostumbran hacer por otros fieles difuntos, se ejecuten piadosa y devotamente según lo establecido por la Iglesia; y que se satisfaga con diligencia y exactitud cuanto se debe hacer por los difuntos, según exijan las fundaciones de los testadores". 4
}

\footnotetext{
${ }^{4}$ Concilio de Trento. Sesión XXV. Decreto sobre el Purgatorio. Que es la IX y última celebrada en tiempo del sumo pontífice Pío IV, principiada el día 3, y acabada en el 4 de diciembre de 1563. El concilio fue convocado en 1545 sin embargo inició en enero de 1546 y finalizó en diciembre de 1563.
} 
Con lo decretado en Trento, la actitud que debían mantener los fieles a la hora de expresar su última voluntad, es la idea del memento mori o el buen morir con la conciencia descargada y el alma preparada. ${ }^{5}$ Este aspecto ha sido estudiando en otras latitudes atendiendo a la voluntad consciente del otorgante que se recalca que el pleno uso de sus facultades mentales y espirituales (Sánchez, 2014). Por ello, el encabezado del testamento no tarda en advertir: iSepan todos cuantos esta carta de testamento y última voluntad vean! Dicha aclaración introductoria "declara la naturaleza jurídica de la escritura testamentaria. La primera se sitúa inmediatamente antes de la identificación del otorgante y la otra inmediatamente después se trata de una fórmula que se refiere al carácter público de la escritura" (Sánchez, 2014, p. 946).6

En el Cuadro 1 se presenta la residencia y año en el cual se elaboró el testamento.

Aun y cuanto la muestra es pequeña esta representa todas las comunidades existentes en la zona norte de la provincia de Costa Rica en el periodo de estudio.7 Esta zona literalmente alcanzaba desde Esparza hasta Nicoya, (Quirós, 1990) todo a lo largo del litoral del Pacífico. Claudia Quirós, ha explicado las razones de su poblamiento colonial.

\footnotetext{
"Debido a las sucesivas invasiones de piratas a Esparza 1685, 1686 y 1687 y sus efectos adversos en el puerto de Caldera, los vecinos de esta localidad decidieron trasladarse hacia los valles de Bagaces, Chomes y Tempisque". Así lo que se ha llegado a denominar como los "valles de Bagaces" bien comprenden tierras que van desde Esparza hasta el río El Salto que marcaba el límite con la Alcaldía Mayor de Nicoya." (Quirós, 1990, p. 262).
}

\footnotetext{
${ }^{5}$ Los decretos insisten en que los sacerdotes expliquen los aspectos doctrinales más destacados para la formación de la feligresía. Catecismo de Santo Concilio de Trento para los párrocos. (1846). Cap. VI. "Del sacramento de la extremaunción", Madrid.

${ }^{6}$ Veáse también Gadow, Reder. (1986). Morir en Málaga. Testamentos malagueños del siglo XVIII. Málaga: España, pp. 17-21. López, Sotelo. (1999). "Sociología testamentaria en Badajoz durante el siglo XVIII". En: Revista de estudios extremeños. T. XLVI, pp. 171-229. Polanco Melero, M. (2001). Muerte y sociedad en Burgos en el siglo XVI. Salamanca, pp. 49- 83.

${ }^{7}$ Hemos insistido en que los siglos XVIII y XIX presentan 5 núcleos estables de población en el pacífico norte de Costa Rica, que luego se llamará provincia de Guanacaste. Estos son: Cañas, Bagaces, Liberia (también llamado Guanacaste), Santa Cruz y Nicoya. La constitución de estos 5 espacios geográficos lo estamos investigando a través del proyecto de investigación titulado: Territorios y territorialidad en Guanacaste: 17001890. Proyecto de investigación. Universidad de Costa Rica. Sede Guanacaste. En desarrollo.
} 
Cuadro 1. Muestra de mujeres testamentarias en Guanacaste. 1769-1826. ${ }^{8}$

\begin{tabular}{|l|l|l|}
\hline \multicolumn{1}{|c|}{ Nombre } & \multicolumn{1}{|c|}{ Lugar } & Año \\
\hline 1. Mónica Corral & Bagaces & 1787 \\
\hline 2. Antonia Colindres & Bagaces & 1799 \\
\hline 3. Manuela López & Bagaces & 1849 \\
\hline 4. María Padilla & Bagaces & 1774 \\
\hline 5. Ma. Mercedes Padilla & Esparza & 1775 \\
\hline 6. Antonia Hurtado & Guanacaste & 1826 \\
\hline 7. María López & Nicoya & 1775 \\
\hline 8. María Josef Morales & Santa Cruz & 1792 \\
\hline 9. Margarita Moraga & Santa Cruz & 1793 \\
\hline 10. Ma. Paulina López & Bagaces & 1793 \\
\hline 11. Juana Gertrudis Sequeira & Santa Cruz & 1799 \\
\hline 12. Juana Gertrudis Viales & Nicoya & 1797 \\
\hline 13. Ma. Concepción Naranjo & Bagaces & 1799 \\
\hline 14. Mercedes Araujo & Guanacaste & 1800 \\
\hline 15. Manuela Carmona & Nicoya & 1769 \\
\hline 16. Damiana Artola & Sardinal & 1812 \\
\hline 17. Juana Sequeira & Nicoya & 1802 \\
\hline 18. Benita Rosales & Nicoya & 1801 \\
\hline
\end{tabular}

Fuente: Elaboración propia con base en fuentes de Archivo Nacional de Costa Rica.

El dispositivo testamentario ha sido explicado en textos como los ya citados (Velásquez y Moya, 2012) pero valga recordar que en nuestro caso, todos los testamentos son abiertos o nuncupativos, por lo que ante la presencia de un escribano público y con presencia de testigos, las testamentarias hacen su declaración. A continuación, en el Cuadro 2 el resumen de sus cualidades.

\footnotetext{
${ }^{8}$ Archivo Nacional de Costa Rica. Protocolos Coloniales. N¹64. Fs.14,14-v,15. 2. A.N.C.R. Protocolos Coloniales. Fs.46,49. 3. A.N.C.R. Protocolos Coloniales. \#396. F.1. 4. A.N.C.R. Protocolos Coloniales. \#147. Fs. 10, 11, 11-v, 12, 12-v, 13, 13-v, 14. 5. A.N.C.R. Protocolos Coloniales. \#149. Fs. 9, 10, 10-v, 11. 6. A.N.C.R. Protocolos Coloniales. \#242. F. 6. 7. A.N.C.R. Protocolos Coloniales. \#148. Fs. 6, 7,7-v, 8, 8-v, 9. 8. A.N.C.R. Protocolos Coloniales. \#180. F.12. 9. A.N.C.R. Protocolos Coloniales. \#180. Fs. 5, 6, 6-v, 7, 7-v. 10. A.N.C.R. Protocolos Coloniales. \#180. F. 2-v. 11. A.N.C.R. Protocolos Coloniales. \#194. F. 32. 12. A.N.C.R. Protocolos Coloniales. \#194. F.35. 13. A.N.C.R. Protocolos Coloniales. \#195. F.1. 14. A.N.C.R. Protocolos Coloniales. \#195. Fs. 22-v, 23-v. 15. A.N.C.R. Protocolos Coloniales. \#139. F.129-v. 16. A.N.C.R. Protocolos Coloniales. \#216. F. 10-v. 17. A.N.C.R. Protocolos Coloniales. \# 200. F. 19-v. 18. A.N.C.R. Protocolos Coloniales. \#198. F.15.
} 
Revista Herencia, Vol. 33 (2), julio-diciembre, 2020.

Cuadro 2. Características principales de las mujeres testamentarias guanacastecas. 1769-1826. ${ }^{9}$

\begin{tabular}{|c|c|c|c|c|}
\hline Nombre & Estado civil & Hijos & $\begin{array}{c}\text { Principales bienes } \\
\text { declarados }\end{array}$ & Ubicación \\
\hline 1. Mónica Corral & $\begin{array}{l}\text { Casada } 2 \\
\text { veces }\end{array}$ & $\begin{array}{l}2 \\
\text { hijas }\end{array}$ & $\begin{array}{l}3 \text { casas pajizas con } \\
\text { corral, } 500 \text { reses, } 12 \\
\text { bestias mulares y } 15 \\
\text { caballos }\end{array}$ & Corobicí \\
\hline 2. Antonia Colindres & Casada 1 vez & $-\cdots$ & $\begin{array}{l}3 \text { casas pajizas con } \\
\text { menaje en tierras } \\
\text { realengas con } 500 \\
\text { matas de plátano }\end{array}$ & Bagaces \\
\hline 3. Manuela López & $\begin{array}{l}\text { Casada } 2 \\
\text { veces }\end{array}$ & $\begin{array}{l}11 \\
\text { hijos }\end{array}$ & $\begin{array}{l}1 \text { casa en San José y } \\
\text { otra en Bagaces } \\
\text { valorada en } 800 \\
\text { pesos }\end{array}$ & Bagaces \\
\hline 4. María Padilla & Casada 1 vez & $\begin{array}{l}4 \\
\text { hijos }\end{array}$ & $\begin{array}{l}300 \text { pesos y } 1 \\
\text { hacienda de ganado } \\
\text { con } 159 \text { cabezas, } 115 \\
\text { yeguas, y } 22 \text { caballos }\end{array}$ & $\begin{array}{l}\text { San Vicente } \\
\text { del Bejuco }\end{array}$ \\
\hline 5. Ma. Mercedes Padilla & Casada 1 vez & 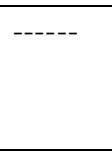 & $\begin{array}{l}\text { Hacienda con } 100 \\
\text { reses, } 50 \text { yeguas, } 10 \\
\text { caballos y } 10 \text { mulas. }\end{array}$ & Bejuquillo \\
\hline 6. Antonia Hurtado & Casada 1 vez & 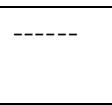 & Hacienda de ganado & $\begin{array}{l}\text { La Hedionda, } \\
\text { Guanacaste }\end{array}$ \\
\hline 7. María López & $\begin{array}{l}\text { Casada } 2 \\
\text { veces }\end{array}$ & $\begin{array}{l}3 \\
\text { hijos }\end{array}$ & $\begin{array}{l}1 \text { esclava nombrada } \\
\text { María de los Santos, } 1 \\
\text { hacienda de ganado } \\
\text { vacuno y caballar }\end{array}$ & $\begin{array}{l}\text { San Joseph de } \\
\text { Humo }\end{array}$ \\
\hline 8. María Josef Morales & Casada 1 vez & $\begin{array}{l}3 \\
\text { hijos }\end{array}$ & $\begin{array}{l}1 \text { casa pajiza con } \\
\text { enseres }\end{array}$ & Nicoya \\
\hline 9. Margarita Moraga & Casada 1 vez & 1 hija & $\begin{array}{l}1 \text { hacienda de } \\
\text { ganado llamada } \\
\text { "Talolinga" }\end{array}$ & $\begin{array}{l}\text { Bolsón y } \\
\text { Humo }\end{array}$ \\
\hline
\end{tabular}

9 Archivo Nacional de Costa Rica. Protocolos Coloniales. No164. Fs.14,14-v,15. 2. A.N.C.R. Protocolos Coloniales. Fs.46,49. 3. A.N.C.R. Protocolos Coloniales. \#396. F.1. 4. A.N.C.R. Protocolos Coloniales. \#147. Fs. 10, 11, 11-v, 12, 12-v, 13, 13-v, 14. 5. A.N.C.R. Protocolos Coloniales. \#149. Fs. 9, 10, 10-v, 11. 6. A.N.C.R. Protocolos Coloniales. \#242. F. 6. 7. A.N.C.R. Protocolos Coloniales. \#148. Fs. 6, 7,7-v, 8, 8-v, 9. 8. A.N.C.R. Protocolos Coloniales. \#180. F.12. 9. A.N.C.R. Protocolos Coloniales. \#180. Fs. 5, 6, 6-v, 7, 7-v. 10. A.N.C.R. Protocolos Coloniales. \#180. F. 2-v. 11. A.N.C.R. Protocolos Coloniales. \#194. F. 32. 12. A.N.C.R. Protocolos Coloniales. \#194. F.35. 13. A.N.C.R. Protocolos Coloniales. \#195. F.1. 14. A.N.C.R. Protocolos Coloniales. \#195. Fs. 22-v, 23-v. 15. A.N.C.R. Protocolos Coloniales. \#139. F.129-v. 16. A.N.C.R. Protocolos Coloniales. \#216. F. 10-v. 17. A.N.C.R. Protocolos Coloniales. \# 200. F. 19-v. 18. A.N.C.R. Protocolos Coloniales. \#198. F.15. 
cont. Cuadro 2.

\begin{tabular}{|c|c|c|c|c|}
\hline Nombre & Estado civil & Hijos & $\begin{array}{c}\text { Principales bienes } \\
\text { declarados }\end{array}$ & Ubicación \\
\hline 10. Ma. Paulina López & $\begin{array}{l}\text { Casada } 3 \\
\text { veces }\end{array}$ & $\begin{array}{l}2 \\
\text { hijos }\end{array}$ & $\begin{array}{l}1 \text { hacienda con } 150 \\
\text { reses, } 20 \text { yeguas y } 8 \\
\text { caballos }\end{array}$ & Cebadilla \\
\hline $\begin{array}{l}\text { 11. Juana Gertrudis } \\
\text { Sequeira }\end{array}$ & Casada 1 vez & $\begin{array}{l}2 \\
\text { hijos } \\
1 \text { hija }\end{array}$ & $\begin{array}{l}20 \text { caballerías de } \\
\text { tierra }\end{array}$ & Santa Cruz \\
\hline 12. Juana Gertrudis Viales & $\begin{array}{l}\text { Casada } 2 \\
\text { veces }\end{array}$ & 1 hija & $\begin{array}{l}\text { Casa pajiza con } \\
\text { enseres }\end{array}$ & Nicoya \\
\hline $\begin{array}{l}\text { 13. Ma. Concepción } \\
\text { Naranjo }\end{array}$ & $\begin{array}{l}\text { Casada } 2 \\
\text { veces }\end{array}$ & ----- & $\begin{array}{l}\text { Casa de campo con } \\
\text { menaje }\end{array}$ & Bagaces \\
\hline 14. Mercedes Araujo & Casada 1 vez & $\begin{array}{l}1 \\
\text { hijo }\end{array}$ & $\begin{array}{l}\text { Hacienda San Joseph } \\
\text { más } 8 \text { caballerías de } \\
\text { tierra. } 4000 \text { pesos, } \\
744 \text { reses, } 50 \text { yeguas, } \\
28 \text { caballos y } 1 \\
\text { esclava }\end{array}$ & Guanacaste \\
\hline 15. Manuela Carmona & $\begin{array}{l}\text { Casada } 2 \\
\text { veces }\end{array}$ & $\begin{array}{l}2 \\
\text { hijos } \\
2 \\
\text { hijas }\end{array}$ & $\begin{array}{l}70 \text { reses, } 40 \text { yeguas y } \\
7 \text { caballos más una } \\
\text { caballería de tierra }\end{array}$ & $\begin{array}{l}\text { Santa Isabel } \\
\text { de Nicoya }\end{array}$ \\
\hline 16. Damiana Artola & Casada 1 vez & $\begin{array}{l}2 \\
\text { hijos } \\
3 \\
\text { hijas } \\
\end{array}$ & 7 caballerías de tierra & Sardinal \\
\hline 17. Juana Sequeira & Casada 1 vez & $\begin{array}{l}2 \\
\text { hijos } \\
1 \text { hija }\end{array}$ & 1 caballería de tierra & Santa Cruz \\
\hline 18. Benita Rosales & Casada 1 vez & $\begin{array}{l}---- \\
\end{array}$ & $\begin{array}{l}22 \text { cabezas de } \\
\text { ganado vacuno y } \\
\text { caballar y una casa } \\
\text { pajiza con menaje }\end{array}$ & Peña Blanca \\
\hline
\end{tabular}

Fuente: Elaboración propia con base en fuentes del Archivo Nacional de Costa Rica.

El Cuadro 2 nos ofrece datos muy relevantes de las mujeres testamentarias. Se observa que la gran mayoría contraen nupcias más de una vez. Esta es una práctica muy usual tanto en el norte de Costa Rica como el sur de Nicaragua en el contexto de la hacienda ganadera. Contraer segundas nupcias aumentaba sustancialmente el patrimonio de las mujeres, ya sea por la dote que ofrecía el marido -en ganado, dinero y tierras- o ya fuera por la ampliación de la red de 
negocios con otras familias ganaderas. Se trata efectivamente de mujeres con arraigo y parentela ganadera. Sus haberes no son nada despreciables, solamente por citar, veamos el caso de Damiana Artola, quien declaró 7 caballerías de tierra en lo que hoy llamamos Sardinal. O Juana Sequeira -madre de Bernabela Ramos- quien declaró 20 y tantas caballerías de tierra a su haber y estaba casada con Juan Ramos, rico ganadero y dueño de más de 50 caballerías de tierra en la zona de Santa Cruz.

Existen otras particularidades de las mujeres testamentarias. Por ejemplo la gran mayoría declaran poseer en promedio "un solar de entre 20 y 40 varas" con corral de "hinchamiento" y casas en su mayoría pajizas, esto es de paredes de bahareque y techo de palma con horcones de madera. El ganado se distribuye entre caballar, mular, reses y todas poseen granja de ovíparos. Su localización va desde los "valles de Bagaces" hasta la Alcaldía Mayor de Nicoya.

En los testamentos destacan entre otros cuatro componentes: a. declaración de fe, devocional y mandas forzozas, b. declaración de estilo de sepelio, c. declaración de estado civil parentela y dote y, d. declaración de bienes. Las 2 primeras corresponden a aspectos propiamente espirituales y de obligaciones de las fieles con la Iglesia Católica. En cuando a las 2 siguientes, nos llevan a aspectos relacionados con la disposición del patrimonio.

A- "Accidentada de la enfermedad que Dios nuestro Señor ha sido servido darme": la declaración de fe de las mujeres testamentarias

El primer segmento que compone el documento testamental es aquel en el cual se expresa la filiación cristiana de las personas. Es el reconocimiento explícito de que la muerte "por venir" es la voluntad de Dios, y por ello se realiza esta acción jurídico-espiritual preparatoria. Así, María Padilla residente en Bagaces en 1774, suscribe su última voluntad replicando que

\footnotetext{
"firmemente creo en el altísmo misterio de la Santísima Trinidad, Padre, Hijo y Espíritu Santo, tres personas distintas y un solo Dios verdadero y en todo los demás que tiene cree y confiesa Nuestra Santa Madre Iglesia Católica Apostólica Romana regida por el Espíritu Santo debajo de cuya fe he vivido y protexto vivir y morir". ${ }^{10}$
}

Para complementar la declaración de fe y su devocional, Benita Rosales vecina de Nicoya manifestó en 1801

${ }^{10}$ Archivo Nacional de Costa Rica. Protocolos coloniales. \#147. F.10. 


\begin{abstract}
"que saque de mis bienes un ternero para Nuestro Sr. San Blas de este pueblo el que se le entregará a su mayordomo...y que después de mi fallecimiento se me saque de mis bienes el valor de 9 misas rezadas por mi alma las que se pagarán a este Sr. Vicario". ${ }^{11}$
\end{abstract}

En el mismo sentido, Manuela López de 70 años quien residió en Bagaces se apuró a indicar que "del quinto de mis bienes pagada la deuda del Lazareto si alcanzare se me dirán las 30 misas de San Gregorio y un novenario de misas si alcanza y sino lo que sea se me dirán misas por mi ánima". ${ }^{12}$

Con suma frecuencia la declaración de fe y devocionales derivó en la fundación de alguna obra pía, en la que por supuesto las preces se direccionaban hacia al alma de la "futura difunta". Este es el caso de Margarita Moraga quien en su viudez dejó establecido que se imponga

\footnotetext{
"un real patronato de legos a título de mayorazgo del puesto de 200 pesos de principal que se han de reconocer en 100 cabezas de ganado vacuno y caballar al precio de 2 pesos cabeza...cuyo rédito deberá ser de 10\% anuales los cuales invertirá el poseedor en otras santas misas rezadas aplicadas por mi alma y de mi difunto esposo el capitán Francisco Javier Viales". ${ }^{13}$
}

B. "El cuerpo a la tierra de que fue formado el cual quiero y es mi última voluntad": el sepelio de las testamentarias

De la lectura de los testamentos coloniales, se deduce que se estilaba un solo tipo de sepelio. El procedimiento se divide en dos partes: por un lado estaba el tratamiento al cuerpo "sin vida" y por otro, el ritual funerario. En el primero prevalece el uso de una mortaja simple de tela sin mayores aditamentos y respecto al segundo, la situación depende de la disposición de recursos económicos. Para el sepelio de María Josef Morales, ella deja bien establecido que "después de mi fallecimiento se le de a mi cuerpo eclesiástica sepultura en la Iglesia Parroquial de este pueblo con mortaja blanca y el entierro que sea Ilano... mando a mi albacea que mande decir ocho misas por mi alma pagando la limosna de 8 reales". ${ }^{14}$ Por su parte, Mercedes Araujo de la Villa del Guanacaste, una vez realizada su declaración de fe indicó que

\footnotetext{
${ }^{11}$ Archivo Nacional de Costa Rica Protocolos coloniales \#198. F.15. Nicoya, 31 de agosto de 1801.

${ }^{12}$ Archivo Nacional de Costa Rica. Protocolos coloniales \#396. F.1 Bagaces, 30 de noviembre de 1849.

${ }^{13}$ Archivo Nacional de Costa Rica. Protocolos coloniales \#180. Protocolos de Aurelio José Figueroa y Ríos. Nicoya-Santa Cruz-Guanacaste, 1793. F. 5.

${ }^{14}$ Archivo Nacional de Costa Rica. Protocolos coloniales \#180. f. 12. Protocolos de Aurelio José Figueroa y Ríos. Nicoya-Santa Cruz-Guanacaste. 1792.
} 
"del 1/5 de mis bienes pagado sea ha mi funeral y entierro y demás mandas, del remanente se me impondrá una capellanía por mi alma y la de mis padres a beneficio de la Iglesia parroquial del Guanacaste, para que con sus réditos se costeé la manteca de la lámpara del SSmo. Sacramento y el costo de los músicos para cuando salga a visitar a los enfermos salga con mucho culto y reverencia". ${ }^{15}$

Un aspecto adicional dentro del imaginario religioso que acompaña el tipo de sepelio, es aquel mediante el cual la testamentaria solicita -valiéndose de su condición económica- algún privilegio poco común en el rito funerario. Este es el caso de María Padilla, quien solicitó a su párroco que su cuerpo fuera amortajado con el hábito de "San Francisco" y además que, "mi entierro sea llano junto al altar de Jesús Nazareno al lado del evangelio y si fuere hora competente se me diga una misa rezada en cuerpo presente". ${ }^{16}$

C. "Mi viudez que duró como 9 años por mi pobreza e indigencia": el estado civil, la parentela y la dote en los testamentos

Más de un 95\% de las mujeres testamentarias de la muestra en análisis estuvo casada al menos una vez. Ya se indicó que el matrimonio fue una poderosa herramienta para extender capitales y redes de negocios. Uno de los casos más ejemplarizantes lo tenemos con $D^{a}$ Juana Gertrudis Sequeira, quien testó en 1802 y en su clausula de estado civil y parentela señaló que

\footnotetext{
"soy casada con Miguel Ramos y durante nuestro matrimonio tuvimos y creamos por nuestros hijos a Baltazar, Pablo y Bernabela Ramos...tengo a mi cargo una capellanía con valor de 100 pesos fincados en 4 caballerías de tierra a beneficio de esta Sta. Iglesia para sufragio de mi alma y la de mi finado marido...[también] declaro por mis bienes una caballería de tierra en el sitio de Sta. Cruz de esta jurisdicción compuestas y pagadas a su Majestad cuyo número de tierras ignoro por estar trascordada pero los títulos lo dirán y que paran en poder de mi hija Bernabela". ${ }^{17}$
}

Llama la atención que en los testamentos se acreditan sumas muy bajas en la dote, ya sea del marido o de la mujer, pero una vez que se consolida el testamento "curiosamente" los haberes de la testante se han multiplicado generosamente. María López residente en Nicoya, al contraer nupcias por primera vez, indicó que su marido Joseph Galagarza "no aportó bienes ninguno el dicho mi marido y yo aporté a él como 20 reses y durante el matrimonio de los

15 Archivo Nacional de Costa Rica. Protocolos coloniales \#195. f. 23-v . Mercedes Araujo. Villa del Guanacaste. 24 de noviembre de 1800.

${ }^{16}$ Archivo Nacional de Costa Rica. Protocolos coloniales \#147. f. 10. María Padilla. Bagaces. 24 de noviembre de 1774.

${ }^{17}$ Archivo Nacional de Costa Rica. Protocolos coloniales \#200. f.19-v Juana Gertrudis Sequeira. Nicoya. 1802. 
2 se fueron multiplicando al fallecer mi dicho marido". ${ }^{18}$ No obstante, después de las segundas nupcias de la Sra. López con el Sr. Juan Alberto Mayorga, ésta declara que además de 200 pesos posee "secciones y haciendas de campo gravados con capellanías [así como] una caballería de tierra que entró en mi poder." ${ }^{19}$

Mercedes Araujo de la Villa de Guanacaste, quien se casó con Cayetano Noguera, representa el caso contrario al de la Sra. López, es decir, fue ella quien engrandeció los haberes de su consorte, por ello declaró que "introduje al matrimonio la cantidad de 4 mil y pico de pesos según consta por mi hijuela y el dicho mi marido no aportó cosa alguna al matrimonio". ${ }^{20}$ Una situación similar presentó Manuela Carmona residente en Nicoya y que declaró, "que fui casada con Joseph Cubillo de cuyo matrimonio tuvimos procreamos por nuestros hijos legítimos a María Antonia y Nicolás...cuando contrajimos matrimonio trajo el dicho mi marido 7 caballos mansos y yo traje 40 yeguas y 70 reses". ${ }^{21}$

D. "Declaro por mis bienes una casa de paja embarrada de vivienda": la declaración de bienes de las testamentarias guanacastecas

Las 18 mujeres testamentarias que componen esta muestra de análisis ostentan bienes de toda índole. Dichos bienes van desde objetos personales como joyas hasta fincas y ganado. En la declaración testamental de bienes no hay un patrón en cuanto a la disposición de los mismos, aunque si existe precisión en su cantidad y atributos. Mónica del Corral dueña de la Hacienda "Corobicí" en Cañas, describe su heredad como:

\footnotetext{
"una casa pajiza de madera redonda sobre horcones y bahareque de 16 varas y 8 de ancho, con su cocina de 8 varas de largo y como 6 de ancho así mismo otras 2 casas la una en del mismo tamaño de esta última dicha y la otra de chiquero de 14 varas y su correspondiente ancho ambas del material de la primera, 2 corrales sin cimiento y buena madera, el uno de 50 y el otro de 40 varas en cuadro...500 reses de primera para arriba, 12 bestias mulares, 1 burro, 38 yeguas, 15 caballos mansos, 3 potros capones y 2 enteros... 3 hachas castellanas y 2 hechizas, 3 machetes, 2 buenos y 1 viejo, una canoa de leche grande y otra pequeña, 5 taburetes, 5 cujas una con su cerradura y llave, una cuja, 3 piedras de moler y una romana grande con mi fierro de herrar con 2 candeleros de bronce amarillo y un par de petacas con sus cadenas". ${ }^{22}$
}

${ }^{18}$ Archivo Nacional de Costa Rica. Protocolos coloniales \#148. F. 6. María López. 1 de abril de 1775. Nicoya. ${ }^{19}$ Archivo Nacional de Costa Rica. Protocolos coloniales \#148. F.7. María López. 1 de abril de 1775. Nicoya.

20 Archivo Nacional de Costa Rica. Protocolos coloniales \# 195. F. 23-v. Mercedes Araujo. Villa del Guanacaste. 24 de noviembre de 1800.

21 Archivo Nacional de Costa Rica. Protocolos coloniales. \#139. F. 129. Nicoya, 4 de junio de 1769.

${ }^{22}$ Archivo Nacional de Costa Rica. Protocolos coloniales. \#164. f 15-v. Mónica del Corral. Bagaces. 16 de mayo de 1787 . 
Otra de las testamentarias que resaltan por la cantidad de bienes declarados fue Damina Artola. "Hija legítima" de Juan Artola e Isabel Mairena procedentes de la villa de Nicaragua, desarrollaron su actividad económica con base en la ganadería. Como era de esperar heredaron a su hija Damiana sus tierras, ganado y demás haberes. Su declaración de bienes señala:

"Declaro por mis bienes 7 caballerías de tierra que constan de 2 escrituras en este sitio del Sardinal, las casas de mi morada y todos los animales que se encuentren con mi fierro así en este sitio como fuera de él, igualmente todos los demás bienes muebles y cualesquiera otra cosa que se reconozca ser mía". ${ }^{23}$

A fines de noviembre de 1774 Maria Padilla realizó su testamento en el poblado de Bagaces. Ella era la dueña de una hacienda de ganado en el sitio nombrado San Vicente del Bejuco. Poseía una casa de 9 varas de largo y 5 de ancho, en ella sobresalían las figuras de San Francisco, San Antonio y un pequeño altar con un crucifijo. Para proteger la propiedad de su ganado ella diseñó su propio fierro.

Además de ganado y tierras, María era la administradora de una capellanía por 200 pesos de plata sentada en la ciudad de Cartago y de la cual se hacía cargo de los rezos, el Lic. Manuel de los Ángeles Montes de Oca. Otros bienes testados por Da María Padilla fueron:

"1 silla y 1 taburete, 1 mesa, 1 canoa con sus llaves, 1 tinajero, 3 pares de naguas, 2 cherlas y 1 estampada, 1 camisa, 1 fustán de lienzo, 1 mantilla de franela guarnesida con listón de media tela de oro, 1 aretes de plata sobre dorados, 1 juego de hevillas de plata, 1 caja con su llave ...[también] 1 corral de hinchamiento [linchamiento] de 40 varas, 150 cabezas de ganado vacuno, 115 yeguas, 1 burro, 1 pollino, 22 caballos mansos todo marcado con los fierros" ${ }^{24}$

María Paulina López, radicaba en los valles de Bagaces a fines del siglo XVIII. Fue hija de hija de Rosa Alvarado y Tomás López, ambos finqueros de la zona. Ella tenía su casa propia de 8 varas de largo y con una cocina de 6 varas cubierta de paja en el sitio nombrado Cebadilla. Ganadera por tradición, tenía un corral de hinchamiento con 40 reses de 6 varas de largo. Tenía lo que llamaba "canoa" o depósito para colocar agua y pasto para las reses. Trabajó el ganado de carne y lechero. En su testamento heredó a sus deudos:

\footnotetext{
${ }^{23}$ Archivo Nacional de Costa Rica. Protocolos coloniales \#216. f.10-v Damiana Artola. Hija legitima de Juan Artola y Isabel Mairena. 16 de noviembre de 1812. Damiana Artola fue casada con Teodoro Jacome con quien tuvo por hijos a María Tiburcia, Toribio José, María Saturnina, María Manuela, y José Lucindo.

24 Archivo Nacional de Costa Rica. Protocolos coloniales \#147. fs. 10, 12. Testamento de María Padilla. Bagaces. 24 de noviembre de 1774.
} 
"una mesa de dos varas, una silla de sentarse, un banco de tinajas, y un taburete...un baúl con cerradura corriente de una vara de largo, una imagen de María Santísima de bulto con su corona de plata, una cruz y dos estampas viejas, una hebilla de plata con peso de 7 onzas, dos naguas de estampado, dos camisas de estopilla, cinco huipiles, un sillón viejo de mi uso, un freno y una martilla negra...una caballería y media de tierra medida compuesta con su majestad en el dicho paraje de la Cebadilla". ${ }^{25}$

Santa Cruz y Nicoya son territorios emblemáticos en el desarrollo de la ganadería durante el siglo XVIII. No solo había ganaderos, había ganaderas dedicadas por completo dicha actividad productiva. Una de ellas fue Margarita Moraga quien radicaba en la zona colindante a Puerto Humo y Bolsón. En dicho territorio heredó de su esposo Francisco José Viales una una caballerías de cuyo número no tenía claro conocimiento y una hacienda llamada Talolinga. Al prepararse para la "vida eterna", Da Margarita recalcó mandar a sus albaceas

"que después de mi fallecimiento repartan 100 pesos entre los pobres de este pueblo así hombres como mujeres...[además de poseer] una hacienda de ganado vacuno, caballar y mular cuyo número de cabezas de cada especie ignoro pero se tendrán por bienes míos todos los ganados bestias y mulas que se encontrasen con mi fierro y señal". ${ }^{26}$

Mercedes Araujo radicaba en la Villa del Guanacaste en 1800. Contrajo nupcias con Cayetano Noguera y sus padres Andrés Araujo y Bernarda Guzmán, le heredaron su hacienda ganadera y un capital de poco más de 4000 pesos de plata. En su última voluntad, expresó que su patrimonio heredable consistía en:

"una hacienda nombrada San Joseph, con posesión de casa, corrales cuya hacienda se compone de 8 caballerías de tierra medidas y pagadas a su merced, 744 reses, 50 yeguas y 28 caballos, 1 candelero de plata, y una esclava... Declaro tener en la villa de Nicaragua un solar con 25 varas de frente y 50 de fondo". ${ }^{27}$

Existe una peculiaridad adicional dentro de los testamentos analizados, y es que buena parte de las testamentarias declaraban "préstamos" y "deudas" con suma frecuencia. Muchas de ellas, en cabezas de ganado y otras en dinero efectivo. El Cuadro 3 resume este aspecto.

${ }^{25}$ Archivo Nacional de Costa Rica. Protocolos coloniales \#180. F.2-v. Protocolos de Francisco Madriz y Santiago Bonilla.1793.

${ }^{26}$ Archivo Nacional de Costa Rica. Protocolos coloniales \#180. Fs.5,6,7. Protocolos de Aurelio José Figueroa y Ríos. 1793. La Sra. Moraga estaba emparentada con la familia de Manuel y Cupertino Briceño.

${ }^{27}$ Archivo Nacional de Costa Rica. Protocolos coloniales \# 195. F. 22-v. Mercedes Araujo. Villa del Guanacaste. 24 de noviembre de 1800. 
Cuadro 3. Deudas por pagar mediante bienes testados.

\begin{tabular}{|c|c|}
\hline Nombre & Deuda testada \\
\hline $\begin{array}{l}\text { María } \\
\text { Mercedes } \\
\text { Padilla }\end{array}$ & $\begin{array}{l}\text { "Francisco Cháves vecino de Nicoya } 3 \text { pesos, } 4 \text { a Joseph Rubí, y } 1 \text { peso y } 4 \\
\text { reales a Anselmo de Alvarado, } 1 \text { res de } 3 \text { pesos a Manuel Hidalgo". }\end{array}$ \\
\hline María & "Juan Rodríguez 13 pesos. A Ambrosio Mayorga vecino de la ciudad de León \\
\hline López ${ }^{29}$ & $\begin{array}{l}12 \text { pesos. A Cayetano de Nicaragua } 5 \text { pesos. A Domingo Solano } 5 \text { pesos. A } \\
\text { Manuel Ruíz } 3 \text { pesos. A Ubaldo Briceño vecino de Nicaragua } 4 \text { pesos". }\end{array}$ \\
\hline $\begin{array}{l}\text { Margarita } \\
\text { Moraga }^{30}\end{array}$ & $\begin{array}{l}\text { "Mi yerno Manuel Briceño me es deudor de la cantidad de } 500 \text { pesos. El Sr. } \\
\text { cura vicario Luis Demetrio de Coronado me es deudor de la cantidad de } 1000 \\
\text { pesos y } 100 \text { pesos más que le presté en dinero en confianza de que no me ha } \\
\text { hecho obligación". }\end{array}$ \\
\hline $\begin{array}{l}\text { María } \\
\text { Padilla } 31\end{array}$ & $\begin{array}{l}\text { "A Timoteo Granja } 13 \text { pesos, al Capitán Joseph Miguel Ruíz } 30 \text { pesos, } 1 \text { peso } \\
\text { a Joseph Sandoya, } 1 \text { peso a Juan Ulate, } 4 \text { pesos a Antonio Pao, } 5 \text { pesos a } \\
\text { Cayetano de la Cerda, } 9 \text { pesos a Juan Jacinto Orozco. Mis deudas espirituales } \\
\text { son: al Señor de la Encarnación de la Villa de Nicaragua } 25 \text { visitas con } 25 \\
\text { candelas, } 1 \text { misa a San Blas de Nicoya, } 2 \text { días de vela con } 4 \text { candelas a San } \\
\text { Joseph de esta villa, } 1 \text { visita y } 1 \text { misa a Nuestra Señora de la Concepción de } \\
\text { esta villa, } 1 \text { misa y visita a San Antonio Adriano. } 1 \text { niñito de plata de } 1 / 2 \text { onza y, } \\
1 \text { peso de plata a Nuestra Señora del Pueblo Viejo más } 5 \text { días de vela y } 5 \\
\text { misas". }\end{array}$ \\
\hline Juana & \\
\hline $\begin{array}{l}\text { Gertrudis } \\
\text { Viales }^{32}\end{array}$ & $\begin{array}{l}\text { "Mi hermana Mauricia Viales me debe } 84 \text { pesos } 2 \text { reales y de estos me ha } \\
\text { pagado en cabezas de ganado vacuno al precio de } 2 \text { pesos cabeza los que } \\
\text { dirá mi hermano el capitán Lucas Viales. Juan Antonio Leiva me debe } 71 \text { pesos } \\
\text { que le presté los que se cobrarán por mis albaceas. Juan Andrés Oquendo } \\
\text { me debe } 4 \text { fanegas y } 1 / 2 \text { de sal". }\end{array}$ \\
\hline Mercedes & \\
\hline $\begin{array}{l}\text { Araujo } 33 \\
\text { Manuela }\end{array}$ & $\begin{array}{l}\text { "Declaro deber } 25 \text { pesos de reales a mi padre San Antonio Adriano del pueblo } \\
\text { de Managua los que tengo ofrecidos de limosna para ayuda a su templo". }\end{array}$ \\
\hline Carmona ${ }^{34}$ & $\begin{array}{l}\text { "A Mauricio Vallejos } 6 \text { pesos...Gabriel Navarro } 3 \text { pesos a Francisco Cerda } \\
\text { vecino de Nicaragua } 20 \text { pesos. Eugenio Dinarte una ternera de año". }\end{array}$ \\
\hline
\end{tabular}

Fuente: Elaboración propia con base en fuentes del Archivo Nacional.

\footnotetext{
${ }^{28}$ Archivo Nacional de Costa Rica. Protocolos coloniales \#149. Fs 9,10-v, 11.

${ }^{29}$ Archivo Nacional de Costa Rica. Protocolos coloniales \#148. F6. 1 de abril de 1775.

${ }^{30}$ Archivo Nacional de Costa Rica. Protocolos coloniales -\#180. F.5. Protocolos de Aurelio José Figueroa y Ríos.1793.

${ }^{31}$ Archivo Nacional de Costa Rica. Protocolos coloniales. \#147. F12-v. Bagaces. 24 de noviembre de 1774.

32 Archivo Nacional de Costa Rica. Protocolos coloniales \# 194. Fs. 10,11,12,13,14. Testamento de Juana Gertrudis Viales. Nicoya. 10 de mayo de 1797.

${ }^{33}$ Archivo Nacional de Costa Rica. Protocolos coloniales \# 195. F.23-v. Mercedes Araujo. Villa del Guanacaste. 24 de noviembre de 1800.

${ }^{34}$ Archivo Nacional de Costa Rica. Protocolos coloniales -\#139. Manuela Carmona. F.129-v. Nicoya, 4 de junio de 1769.
} 


\section{Conclusión}

A lo largo de este artículo hemos tratado de poner en evidencia las prácticas testamentarias de18 mujeres guanacastecas a lo largo del periodo 1774-1812. Si bien la muestra es pequeña, nos sirvió para detectar las formas seguidas para el buen morir en un grupo de población que rara vez es estudiado en el contexto de la hacienda ganadera guanacasteca. La preparación de la conciencia y el alma en la ruta hacia la "vida eterna" de las mujeres hacendadas, se vio matizado por sucesivos encuentros matrimoniales, negocios para la ampliación de los hatos ganaderos y participación constante en la fundación de obras pías.

El Índice de Protocolos de Guanacaste de 1756 elaborado por Manuel De Araya, suministra los indicios principales de los tipos de transacciones más frecuentes en el Pacífico norte del país. Sin embargo, el investigador (a) debe sumergirse en la fuente testamental para entender en su totalidad sus atributos. A pesar de ser esta una fuente que goza de cierta formalidad -por los cánones doctrinarios que le rigen- nos han permitido conocer una parte del imaginario religioso y las situaciones de vida de las mujeres ganaderas testamentarias guanacastecas.

\section{BIBLIOGRAFIA}

\section{Fuentes primarias}

Archivo Nacional de Costa Rica. Protocolos Coloniales. \#164. Fs.14,14-v, 15.

\#644. Fs.46,49.

\#396. F.1.

\#147. Fs. 10, 11, 11-v, 12, 12-v, 13, 13-v, 14.

\#149. Fs. 9, 10, 10-v, 11.6.

\#242. F. 6.

\#148. Fs. 6, 7, 7-v, 8, 8-v, 9.

\#180. Fs. 2-v. Fs. 5, 6, 6-v, 7, 7-v.12.

\#194. Fs. 32, 35.

\#195. Fs.1. 22-v, 23-v.

\#139. F.129-v.

\#216. F. 10-v.

\# 200. F. 19-v.

\#198. F.15. 


\section{Libros y artículos}

Alfaro, F. \& Velázquez, C. (Setiembre 2011- Febrero 2012). Base de Datos de los Testamentos de Cartago, Costa Rica, del Siglo XVII. Diálogos. Revista Electrónica de Historia. Vol. $12 \mathrm{~N}^{\circ} 2$.

Ariès, P. (1992). El hombre ante la muerte, Madrid: Taurus.

Catecismo de Santo Concilio de Trento para los párrocos. (1846). Cap. VI, "Del sacramento de la extremaunción". Sesión XXV. "Decreto sobre el Purgatorio".1563. Impreso en Madrid.

Constituciones sinodales dadas por el Cardenal Pacheco y promulgadas y ahora aumentadas por el arzobispo Cristóbal Vela. Archivo Catedral de Burgos (A.C.B.), cód. n53, fols. 33v-45. Disponible en: http://www.catedraldeburgos.es/

De Araya, M. (1902). Índice de los Protocolos de Guanacaste. San José: Tipografía Nacional. 1756-1852.

Gadow, R. (1986). Morir en Málaga. Testamentos malagueños del siglo XVIII. Málaga: España.

Gudmundson, L. (1983). Hacendados políticos y precaristas: la ganaderia y el latifundio guanacasteco, 1800-1950. San José: Editorial Costa Rica.

Gudmundson, L. (1979). Apuntes para una historia de la ganadería en Costa Rica. Revista de Ciencias Sociales. No17.18.

Gudmundson, L. (1978). Estratificación socio-racial y económica de Costa Rica. 1700-1850. San José: EUNED.

López, S. (1999). Sociología testamentaria en Badajoz durante el siglo XVIII. Revista de estudios extremeños. T. XLVI.

Matarrita, M. (1980). La Hacienda ganadera colonial en el corregimiento de Nicoya, siglo-XVIII.San José: spi. 
Meléndez, C. (1977). Costa Rica: tierra y poblamiento en la colonia. San José: Editorial Costa Rica.

Melero, M. (2001). Muerte y sociedad en Burgos en el siglo XVI. Salamanca.

Moya, A. (1991). "El Rito Mortuorio en el Cartago Dieciochezco". Revista de Historia. N. ${ }^{\circ} 24$ (julio).

Ortego, M. Á. (1999). Familia y matrimonio en la España del siglo XVII: ordenamiento jurídico y situación real de las mujeres a través de la documentación notarial. Tesis doctoral. Universidad Complutense de Madrid. Facultad de Geografía e Historia. Departamento de Historia Moderna.

Rivera, G. (2009). Historia y narrativa. La hacienda ganadera guanacasteca. Análisis de las novelas: "La Estirpe del volcán" y "El festín de los coyotes". (Agosto 2008 - Febrero 2009). Diálogos Revista Electrónica de Historia. Vol. 9 No. 2.

Schumann, A. E. (2012). De la vida terrena a la vida eterna: manifestaciones de religiosidad ante la muerte en testamentos de la Ciudad de Guatemala durante la época colonial. Tesis de Maestría en Historia. Universidad de San Carlos. Escuela de Historia, Guatemala.

Sánchez, R. (2014). El testamento castellano en el siglo XVI: institución jurídica al servicio de la muerte. El mundo de los difuntos: culto, cofradías y tradiciones. España: Universidad de Burgos. San Lorenzo del Escorial.

Sequeira, W. (1985). La hacienda ganadera. Aspectos económicos y sociales. 1850-1900. San José: EUNED.

Quirós, C. (1990). La era de la encomienda. San José: Editorial de la Universidad de Costa Rica. 